\title{
QUEEN'S
UNIVERSITY
BELFAST
}

\section{The impact of information integration on purchase order finance and new product launch: A case study}

Zhang, M., Huang, Q., Zhao, X., \& Ma, L. (2021). The impact of information integration on purchase order finance and new product launch: A case study. International Journal of Operations \& Production Management. https://doi.org/10.1108/IJOPM-06-2020-0377

\section{Published in:}

International Journal of Operations \& Production Management

\section{Document Version:}

Peer reviewed version

\section{Queen's University Belfast - Research Portal:}

Link to publication record in Queen's University Belfast Research Portal

\section{Publisher rights}

Copyright 2021 the authors.

This is an open access Creative Commons Attribution-NonCommercial License (https://creativecommons.org/licenses/by-nc/4.0/), which permits use, distribution and reproduction for non-commercial purposes, provided the author and source are cited.

\section{General rights}

Copyright for the publications made accessible via the Queen's University Belfast Research Portal is retained by the author(s) and / or other copyright owners and it is a condition of accessing these publications that users recognise and abide by the legal requirements associated with these rights.

Take down policy

The Research Portal is Queen's institutional repository that provides access to Queen's research output. Every effort has been made to ensure that content in the Research Portal does not infringe any person's rights, or applicable UK laws. If you discover content in the Research Portal that you believe breaches copyright or violates any law, please contact openaccess@qub.ac.uk. 


\title{
The impact of information integration on purchase order finance and new product
} launch: A case study

\begin{abstract}
Purpose In this study, we examine the implementation of purchase order finance (POF) which is an innovative supply chain finance (SCF) solution by an innovative SCF lender (i.e., supply chain service provider (SCSP)). The effect of information integration between the SCSP (lender) and product designers (borrowers) on the lender's POF decisions and the borrowers' new product launch is investigated.
\end{abstract}

Design/methodology/approach We conduct a case study in the Chinese smartphone industry. A mixed methods design is used, and data are collected from both the SCSP and product designers. We first conduct a qualitative study. Hypotheses are developed concerning the relationships between information integration, in terms of social interaction and information system integration, POF and new product launch. We then conduct a quantitative study. The multilevel structural equation modelling method is used to test the hypotheses.

Findings We find that information system integration is positively associated with POF but has no significant effect on new product launch. Social interaction is negatively associated with POF but positively associated with new product launch. POF is positively associated with new product launch.

Originality/value This study contributes to the literature by empirically examining the implementation of POF from both the lender's and borrower's perspectives. We find that information system integration and social interaction have different effects on POF and new product launch. The results thus provide insights into how a lender makes POF decisions and reveal the benefits of POF for borrowers.

Keywords: information integration, supply chain finance, purchase order finance, new product launch, mixed methods research 


\section{Introduction}

Purchase order finance (POF) is a type of loan a seller obtains from a finance provider based on purchase orders issued by a buyer (Global Supply Chain Finance Forum, 2016; Tang et al., 2018). POF represents an innovative supply chain finance (SCF) solution that covers the seller's working capital requirements, such as the procurement of raw materials and other pre-shipment expenses, thus ensuring that delivery to the buyer is fulfilled (Tang et al., 2018; Reindorp et al., 2015).

The number of small and medium sized enterprises (SMEs) focusing on designing smartphones (i.e., product designers) in China is growing. They aim to sell their innovative products to domestic and overseas buyers. The rapid and successful commercialisation of their new smartphone designs is critical, as it ensures they gain competitive advantages in the industry. However, product designers typically lack production and supply chain management capabilities and face a shortage of working capital to fund the launch of their smartphones (Song et al., 2020). A new product launch involves the physical introduction and delivery of new products to buyers (Jenkins et al., 2020). This is the final stage of the new product development process and involves the largest investment (Kou et al., 2015; Cui et al., 2011; Di Benedetto, 1999). POF has been viewed by product designers as a solution that eases their capital constraints, as they can obtain working capital to support the new product launch using purchase orders from buyers (Liu et al., 2015; Li and Chen, 2019). Studies have shown that SCF solutions can improve supply chain performance and stability by shortening the cash-to-cash cycle and optimising working capital in a supply chain, through a decrease in accounts receivable or an increase in accounts payable (Xu et al., 2018; Jia et al., 2020a). Empirical evidence also reveals that SCF solutions allow supply chains to improve access to finance and decrease financial costs, alleviating their members' financial distress and risks (Caniato et al., 2016; Gelsomino et al., 2016). Although researchers have argued that SCF can encourage innovation (Jia et al., 2020b), evidence for the impact of POF on the launching of new products by SMEs is limited (Chen et al., 2020).

China's inadequate and under-developed credit guarantee and rating systems mean that product designers generally find it difficult to obtain liquidity through conventional bank loans because they have limited fixed assets (Liu et al., 2015). This has been a longstanding issue for the Chinese smartphone industry. Thus, supply chain service providers (SCSPs) who provide value-added services (such as customs clearance, inventory management, logistics, import/export commodity inspection and international settlement) extend their roles and offer 
POF to product designers (Liu et al., 2015; Jia et al., 2020a). SCF solutions have typically been examined from the buyer's perspective (Caniato et al., 2019; Zhao and Huchzermeier, 2019) or in terms of manufacturer-centred financial networks (Jia et al., 2020a). Few studies investigate how SCSPs implement POF (Xu et al., 2018; Chen et al., 2020).

The information asymmetry between lenders and borrowers can be a major issue in SCF (Song et al., 2020). The designers must successfully launch their product designs to repay the POF associated with the purchase orders. Thus, their performance represents a major risk to SCSPs in terms of POF (Wu et al., 2014; Tang et al., 2018). The information product designers hold concerning the likelihood that they can successfully deliver an order according to the defined quality specifications, cost and delivery times will differ from that held by SCSPs (Song et al., 2020; Yamanaka, 2016). Integrating the information between SCSPs and product designers can thus improve supply chain connectivity and transparency, and allows the SCSPs to monitor and control the information and physical flows in supply chains. They can then better evaluate product designers' abilities or willingness to repay loans (Bals, 2019; Reindorp et al., 2015). Information integration refers to the exchange and transfer of information that facilitates collaboration and cooperation among supply chain members through media such as face-to-face meetings, telephone, fax, email and information systems (Cai et al., 2010; Li et al., 2014). Therefore, SCSPs and product designers can integrate information through information system integration and social interaction (Dobrzykowski and Tarafdar, 2015; Huo et al., 2013). Information system integration allows them to integrate information through collaborative activities based on information technologies (ITs) involving software, hardware, applications and databases (Zhang et al., 2018). Social interaction allows them to integrate information based on human involvement and participation and using social linkages and connections (Tsai and Ghoshal, 1998). Information integration enables SCF lenders to identify valuable projects, determine the probability of default, and monitor and control financial risks (Bals, 2019; Chen et al., 2020). Thus, it is central to the application of SCF solutions (Caniato et al., 2016; Martin and Hofmann, 2019). However, the effects of information integration on SCSP decisions regarding POF have not been fully investigated (Gelsomino et al., 2016; Jia et al., 2020a).

The objective of this study is to investigate the effect of information integration between SCSPs (i.e., POF lenders) and product designers (i.e., POF borrowers) on the POF decisions of SCSPs and the launching of new products by the product designers. We address three research questions in this study. First, what are the impacts of information system integration and social interaction on a SCSP's POF decisions? Second, what are the impacts of 
information system integration and social interaction on a product designer's new product launch? Third, what is the impact of POF on a product designer's new product launch? The main contributions of this study are as follows. First, this study presents a case study that focuses on the implementation of an innovative SCF solution (POF) by an innovative lender (SCSP) in the Chinese smartphone industry. Xu et al. (2018) call for more research examining SCF in specific industries. Jia et al. (2020a) find that most SCF studies focus on banks and manufacturers as SCF providers. They call for further investigation into the roles of supply chain orchestrators in providing SCF. In addition, most SCF studies focus on reverse factoring (Bals, 2019) and trade credit (Xu et al., 2018), and other innovative SCF solutions have received less attention (Gelsomino et al., 2016). The lack of empirical research on SCF has also been noted (Liu et al., 2015; Gelsomino et al., 2016; Caniato et al., 2019; Jia et al., 2020b). Using a mixed methods design, we collect qualitative and quantitative data from a POF lender and borrowers. The findings thus provide empirical evidence on different stakeholders' views of POF, enhancing current understanding of POF implementation (Bals, 2019; Xu et al., 2018).

Second, we provide insights into how information integration enables and supports POF. Caniato et al. (2019) highlight the need to address the roles of real-time information and digital technologies in SCF. Bals (2019) calls for a broader discussion of how IT can support SCF. Jia et al. (2020a) note that there is little empirical evidence of how inter-organisational relationships affect SCF implementation. Our research extends the conceptual studies by providing empirical evidence of the distinct effects of information system integration and social interaction on a SCSP's POF decisions (Bals, 2019; Jia et al., 2020a). The findings also provide insights into how POF lenders manage financial risks (Gelsomino et al., 2016; Liu et al., 2015).

Third, we demonstrate the non-financial benefits of SCF solutions by revealing the effects of POF on the launching of new products (Caniato et al., 2019). SCF solutions can bring financial and operational benefits, such as improved supply chain visibility, reduced risk of bankruptcy and strengthened supply chain links (Gelsomino et al., 2016; Xu et al., 2018). Jia et al. (2020b) argue that SCF solutions enable innovation in supply chains, which helps to make them more sustainable. Our study extends the knowledge on the performance outcomes of SCF solutions (Liu et al., 2015).

\section{Literature review}

\subsection{SCF and POF}


Academic interest in SCF is increasing, and several literature reviews of the topic have been conducted. Some aim to identify the main research themes by categorising studies (Liu et al., 2015; Gelsomino et al., 2016; Xu et al., 2018), and others focus on developing conceptual frameworks for the implementation of SCF (Bals, 2019; Jia et al., 2020a; Jia et al., 2020b). These reviews reveal that the current empirical evidence on SCF implementation is limited and fragmented (Bals, 2019; Gelsomino et al., 2016). Few studies have investigated applications of innovative SCF solutions in specific industrial and regional contexts (Gelsomino et al., 2016; Xu et al., 2018). Although SCF has been found to improve operational and financial performance (Xu et al., 2018), the specific performance outcomes beyond financial indicators have not been identified (Caniato et al., 2019; Jia et al., 2020b). Researchers have also noted that the roles of innovative SCF lenders and the interactions between SCF stakeholders are underexplored (Caniato et al., 2019; Jia et al., 2020a). Several researchers have empirically investigated the implementation of SCF solutions using case studies (Wuttke et al., 2013; Caniato et al., 2016; Martin and Hofmann, 2019; Chakuu et al., 2020), but mostly in Western contexts, and applications of POF in China have not been sufficiently examined.

POF is a form of pre-shipment loan provided by a finance provider to a seller of goods (Martin and Hofmann, 2019). A POF transaction involves two main parties: the seller and the finance provider (e.g., financial intermediaries or supply chain partners) (Tang et al., 2018). They enter into a financing agreement detailing the terms of the financing structure (Global Supply Chain Finance Forum, 2016). In a POF transaction, a buyer sends a purchase order to a seller who submits a request for POF to a finance provider, who finances the seller's account. After the seller ships the goods to the buyer, the finance provider debits the principal plus interest from the seller's account on maturity (Global Supply Chain Finance Forum, 2016). Analytical models have been developed to investigate the applications of POF (Reindorp et al., 2015) and to compare it with other SCF solutions (Zhao and Huchzermeier, 2019; Tang et al., 2018; Wu et al., 2014). These reveal the conditions under which POF is an attractive financing option and can improve performance. However, these studies generally take the buyer's perceptive (Tang et al., 2018; Zhao and Huchzermeier, 2019), and the roles of SCSPs in the application of POF and how POF affects a seller's performance have rarely been examined.

\subsection{New product launch}

New product launches involve commercial manufacturing and supply chain management activities (Takeuchi and Nonaka, 1986; Schoenherr and Swink, 2015). A successful new 
product launch requires firms to transfer new product designs to commercial manufacturing with high speed and quality (Kou et al., 2015). Efficient and effective production and logistics management are therefore critical (Jenkins et al., 2020; Schoenherr and Swink, 2015). Launching new products can be risky and time-consuming. The expenditure incurred often exceeds that of all previous new product development activities combined (Cui et al., 2011; Schoenherr and Swink, 2015). Cash-constrained SMEs typically have limited resources for developing supply chains and establishing relationships with service intermediaries when launching new products (Zhang and $\mathrm{Li}, 2010$ ). Thus, obtaining external funding and collaborating with service intermediaries are important for SMEs as they can take advantage of existing networks when commercialising new product designs, which can help them cope with internal and external constraints (Schoenherr and Swink, 2015; Song et al., 2011). Researchers argue that information gathering and operations and supply chain management are important in new product launches (Di Benedetto, 1999). However, the effects SCF solutions and information integration with SCSPs can have on the launching of new products are relatively under-researched (Schoenherr and Swink, 2015; Kou et al., 2015; Cui et al., 2011).

\subsection{Information integration}

Information integration is important to the success of supply chain management (Cai et al., 2010; Huo et al., 2013), and involves various technologies, systems, people and relationships in the knowledge exchange within a supply chain (Dobrzykowski and Tarafdar, 2015). Supply chain members may integrate explicit knowledge such as order specifications, production and inventory capacity and order deliveries, or tacit knowledge such as improvement suggestions and know-how in the design and management of the supply chain and business processes ( $\mathrm{Li}$ et al., 2014). Information system integration requires investment in technology (e.g., information networks and systems) for exchanging and processing explicit knowledge (Huo et al., 2013). It automates and routinizes information sharing, assimilation, storage and distribution to create an information-rich environment (Zhang et al., 2018). This provides a platform for supply chains to link information sources and process large amounts of information quickly at low cost, thus better coordinating the supply chain (Dobrzykowski and Tarafdar, 2015). Social interaction involves links and communication among employees of different firms (Tsai and Ghoshal, 1998) and provides a mechanism through which they can work together, thus enabling the transfer and integration of tacit knowledge (Huo et al., 2013). Employees can gain access to the private information of others through social interaction, thus facilitating cooperation among firms (Villena et al., 2011; Li 
et al., 2014). The diversity and depth of the information exchanged in supply chains will therefore increase (Zhang et al., 2018). Researchers have shown that technologies and supply chain relationships enable the integration of financial and information flows in supply chains (Bals, 2019) and that IT capabilities and social relationship related factors influence the applications of SCF solutions (Martin and Hofmann, 2019; Wuttke et al., 2013; Caniato et al., 2016). However, the effects of information system integration and social interaction between lenders and borrowers on the application of POF have not been empirically confirmed (Caniato et al., 2019; Jia et al., 2020a).

\section{Research methods}

In this study, we combine qualitative and quantitative case study approaches. We use a mixed methods design for three reasons: 1) complementarity, as the mixed methods design allows findings of the qualitative study to be enhanced and those of the quantitative study to be elaborated; 2) diversity, as qualitative and quantitative data are collected from a POF lender and borrowers, and thus the design reflects the diverse views of different stakeholders; and 3) triangulation, as combining data from multiple sources enables us to establish whether the findings from qualitative and quantitative studies support each other (Saunders et al., 2019).

Theoretical sampling was used to select the case (Yin, 2009). We selected a SCSP (i.e., CJSC) in the Chinese smartphone industry because it is an innovative firm that implements POF in a novel way. CJSC has been acknowledged as one of the most successful SCSPs in the Greater Bay Area of China. The company applies an Internet plus supply chain plus financing' business model and aims to build 'a "joint-win" and "joint-management" chain' and achieve a 'win-win relationship' with product designers. It has developed an E-SCM system and offers supply chain execution (such as customs clearance for imports and exports, international and domestic logistics, and warehouse management) and integration services. CJSC has also made a major effort to integrate information flows with product designers and has developed close collaborative relationships with commercial banks. It has received a combined credit line of 10 billion Chinese Yuan. Product designers in the smartphone industry typically have limited physical assets they can use for collateral and their cash flows are weak, resulting in low credit ratings and hence difficulty in obtaining loans from banks. CJSC's president commented that 'the financing for these product designers is difficult, expensive, and chaotic'. Thus, its supply chain management services and the support from banks have enabled CJSC to offer POF to product designers since 2009, which makes it a 
unique case through which we can empirically explore the implementation of POF (Yin, 2009).

\subsection{Qualitative study \\ 3.1.1 Data collection}

The data sources include semi-structured interviews and secondary data (e.g., company reports and information from the Internet). The triangulation of relevant issues enables the research team to cross-verify the findings (Yin, 2009).

The interviews were guided by a research protocol (Appendix I), which was developed based on the research questions, literature review and secondary data. The project spanned a period of 18 months. The research team interviewed 10 senior managers in CJSC, including the president, director and vice director of the information system department, the director and vice director of the risk control department, the director of the financing department, two business managers and two operations managers. We also interviewed four general managers and one financial manager from four product designers. The interviews lasted two to three hours each, were conducted in Chinese and were audio-recorded. The team members conducted debriefing meetings before and after each interview to share information and experiences and to review the logic and content of the interviews, so they could establish a chain of evidence. The recordings were sent to be transcribed and the results were then translated into English by a professional translator. The research team stayed in informal contact with the managers via telephone and WeChat to clarify the issues raised in the debriefing meetings. A case database was created that includes transcripts, notes, and documents from CJSC and information from the Internet. Our research protocol and the developed case study database helps to ensure the reliability of our research (Yin, 2009). Using multiple data sources and maintaining a chain of evidence also enable us to establish construct validity (Yin, 2009).

\subsubsection{Findings}

We followed Gioia et al.'s (2012) approach to code and analyse the data. During the firstorder analysis, we conducted open coding to disaggregate the data into conceptual units and then coded it with informant-centric terms (Strauss and Corbin, 1990). Then, we used axial coding to identify similarities and differences between the categories of data emerging from the open coding. The categories were then regrouped and linked into each other to identify themes (Strauss and Corbin, 1990). In the second-order analysis, we linked the emerging themes to the researcher-centric concepts and then distilled the concepts further into 
aggregate dimensions. The coding and data structure is presented in Figure 1 and the details of the coding scheme are provided in Appendix II.

Figure 1 about here

\subsubsection{POF}

According to CJSC's president, they manage POF on a project basis and it involves two players: CJSC as the POF lender and product designers who are the borrowers. Product designers sell new smartphone designs to buyers and sign sales contracts with them. They initiate POF projects after they receive the purchase orders. A smartphone includes hundreds of components that may involve suppliers all over the world. A general manager of one of the product designer's said that it 'cannot provide advance payment for purchasing raw materials and components after receiving orders from buyers'. Thus, CJSC provides POF to cover a certain percentage of the product designers' purchasing costs. CJSC must make the key decision about the proportion of the total purchasing cost of raw materials and components that the loan covers, which it determines through an assessment of the risks. Thus, the POF received by the product designers is an amount in Yuan relative to the total purchasing costs. To control the financial risks, CJSC verifies the purchase orders confirmed by the buyers and also requires the product designers to ensure their buyers pay the deposit and retainage directly to CJSC. A financial manager of a product designer commented, 'CJSC helped us evaluate the credit history of an international buyer and the validity of its orders because different buyers used different forms of payments, such as Teletext, Letter of Credit (LC), or even Open Account. CJSC has to be more watchful than us because the LC is sent to CJSC, not us!' Using the POF, CJSC purchases the raw materials and components in international and domestic markets on behalf of the product designers. After finalising the orders, CJSC receives payment from the buyers, which is used to repay the loans (principal and interest) and pay the service fees. CJSC then sends the remainder to the product designers. Thus, the product designers' ability to perform in line with the contract and the ability and willingness of the buyers to pay on delivery of the products are the key risks faced by CJSC in a POF project. Product designers use CJSC's supply chain management services, such as export customs clearance assistance (including paying tax), international and domestic logistics, inventory management (including storage, sorting, and delivery), settlement, and tax refunds. The sourcing of raw materials and components, manufacturing of new products and delivery of products to buyers are thus jointly managed by the product designers and CJSC. As its president commented, CJSC is 'deeply integrated into product designers' 
supply chain processes to control its assets prior to shipment'. The POF provided by CJSC is illustrated in Figure 2. The key differences between this and the traditional POF (Global Supply Chain Finance Forum, 2016) are that instead of directly providing finance to product designers, CJSC uses the fund to purchase raw materials and components for them and is involved in the product designers' operations by providing supply chain management services; furthermore, buyers pay CJSC rather than the product designers.

Figure 2 about here

\subsubsection{New product launch}

The smartphone industry is characterised by hyper-competition, fast-changing consumer tastes, and very short product life cycles. Product designers focus on the research and development (R\&D) of new smartphones and are expanding their businesses into the international markets of the Philippines, Thailand, Pakistan, India and Indonesia. They sell smartphone designs to foreign buyers who rebrand the smartphones to sell in their local markets. Product designers may design new smartphones based on their internal R\&D and then sell them to buyers, or operate as original design manufacturers who develop and produce new smartphones as specified by buyers. One general manager commented that 'successfully commercialising new product designs is critical for us to develop overseas markets.' A successful new product launch increases product designers' profitability and enables them to improve the capacity and flexibility of their operations. All of the product designers' managers agreed that speed is the key to win orders in international markets and introducing and launching new products quickly allows them to gain competitive advantages, particularly in holiday seasons such as Halloween and Christmas. Product designers' targeted buyers are the top five smartphone brand owners/distributors in each foreign country. According to the general managers, introducing high-quality smartphones is critical for their survival and growth in international markets.

\subsubsection{Information integration}

Managers in CJSC and product designers all agreed that their employees share information through social linkages and connections, such as via meetings, conferences, telephone, instant messaging (e.g., QQ and WeChat) and emails. CJSC sometimes sends employees to visit product designers' workplaces. CJSC's business and operations managers explained that communication and interactions between their and product designers' employees enable the product designers to understand how CJSC manages POF projects and to receive support in their supply chain management. Managers in the product designers all mentioned that their 
employees maintain close contact with CJSC to ensure they can solve problems quickly. CJSC's operations managers also commented that they receive suggestions for improvement and technical know-how from product designers through interactions between employees. CJSC's president noted that CJSC and the product designers can align their business processes and coordinate decision-making through frequent social interaction.

CJSC and product designers also exchange information and synchronise data using information systems. CJSC has focused considerable effort and resources on IT and has developed an E-SCM system that includes a range of software and applications. The director of CJSC's information system department explained that CJSC uses the SAP ERP system as the backbone of its IT infrastructure, and it has an IBM Si integrated data centre and an inhouse developed B2B web-based database. Product designers can access the E-SCM system through an Internet portal. He also highlighted that the E-SCM system is 'a common service platform on the Internet to promote fully automated data exchange'. CJSC's president commented that the system enables 'faster communication, shorter lead time, lower transaction cost, lower pipeline inventory, and more effective planning and coordination in supply chains'. CJSC encourages product designers to either use the E-SCM system to manage their supply chains or integrate their information systems with it. Product designers' managers also mentioned that information systems facilitate collaboration with CJSC in terms of supply chain and business process management. Therefore, the case evidence reveals that CJSC and product designers integrate information flows through social interaction and information system integration.

\subsubsection{Impacts of social interaction and information system integration on POF}

CJSC's president noted that CJSC offers POF to product designers 'that have a vision, customer orders, and technology, but lack capital, supply chains, and a strong credit history'. The interactions with product designers' employees help CJSC identify and collaborate with product designers that have compatible cultures, goals and strategies. Social interaction allows CJSC employees and product designers to agree on inter-organisational processes for managing supply chains and POF projects. This also facilitates the exchange of tacit knowledge, such as supply chain partners' capabilities, industrial know-how and suggestions for improvement, which helps product designers solve problems and integrate business processes with CJSC. These can increase the speed and flexibility of the supply chain to ensure the delivery of a buyer's order. CJSC can also accumulate more knowledge about the product designers' strategies and capabilities via social interaction, enabling it to better evaluate POF projects. Therefore, we propose the following hypothesis. 
H1. Social interaction between CJSC and product designers increases the POF received by the product designers.

CJSC's president argued that the 'E-SCM system gives us a control lever for all flows: We can see and control all flows of the data, goods, and money passing through the platform! With this tight control, CJSC has been able to provide financing to its clients who have a hard time getting loans from traditional channels'. Using integrated information systems to manage supply chains and business processes allows CJSC to acquire timely and accurate explicit knowledge about procurement, production, inventory, delivery and settlement from product designers, which improves the transparency of their operations. CJSC also verifies the information by checking the materials and products in supply chains, such as warehouse shelves, assembly lines and trucks. Information system integration thus enables CJSC to integrate operational and financial processes and to monitor and control the physical and financial flows. Thus, it gives CJSC an advantage over banks in managing risks when lending to product designers, as the banks typically cannot control the physical, information and financial flows in supply chains at the operational level. In addition, information system integration furnishes CJSC with a large amount of data on product designers' past supply chain operations and POF projects, giving it a better understanding of product designers' ability to fulfil orders, and enabling it to predict the profitability and risks associated with POF projects. As CJSC's president commented, 'product designers do not necessarily have low credibility. Sometimes, their transactions are scattered around and lack transparency to banks. The E-SCM system gives them a place to aggregate their scattered transactions together with quantifiable data to prove their credibility'. Thus, the use of the information system to exchange information and collaborate on supply chain management enables CJSC to build a 'closed-loop system', which has an essential role in CJSC's risk assessment of a $\mathrm{POF}$ project. The degree of information system integration has become a key criterion when CJSC makes POF decisions. Therefore, we propose the following hypothesis.

H2. Information system integration between CJSC and product designers increases the POF received by the product designers.

3.1.2.5 Impacts of social interaction and information system integration on new product launch

In the interviews, the product designers' managers mentioned that social interaction with CJSC enables them to obtain tacit knowledge about supply chains, even though CJSC does not directly participate in their R\&D. According to CJSC's president, supply chain coordination is one of its core competences. He explained that 'more and more smartphone 
supply chain partners, from foreign clients who make orders to upstream component suppliers and logistics providers, band together to use our supply chain management services. Therefore, I usually say that our supply chain services are "embedded" in the (smartphone) industry'. Thus, CJSC has developed good relationships with various stakeholders in the supply chain and by offering supply chain management services has accumulated knowledge such as changes in customer preferences and market demand, the capabilities and service level of supply chain members, and the quality of components (e.g., displays, speakers and cameras). Active and frequent social connections enable product designers to acquire tacit knowledge about suppliers and technical know-how from CJSC. This knowledge significantly improves the connectivity and transparency in the supply chain, which helps product designers identify high-quality suppliers for the various components and develop a deeper understanding of supply chains, ensuring the successful launch of new products. Social interaction facilitates product designers to obtain support for supply chain management. For example, CJSC offers a 'three in one' supply chain project service, which includes consultation, service and supply chain execution. The meetings and conferences organised by CJSC enable product designers to establish relationships with a bundle of trustworthy and high-quality component suppliers, along with assembly plants, warehouses and logistics service providers. Thus, product designers can collaborate with capable partners and purchase high-quality raw materials and components when launching new products. In addition to ensuring the quality of new products, this collaboration can speed up their introduction to the market. The product designers' managers also mentioned that solving problems related to purchasing, manufacturing, inventory and logistics via social interaction enables them to launch new products quickly. Therefore, we propose the following hypothesis.

H3. Social interaction between CJSC and product designers improves the product designers' new product launch.

The director of CJSC's information system department explained that the E-SCM system provides 'a common infrastructure and protocol to enable real-time information exchange among supply chain members'. Integrating information systems with the E-SCM system allows product designers to obtain real-time transaction data on component purchasing, logistics, inventory management and delivery. The director also mentioned that the E-SCM system collects extensive explicit knowledge in areas such as the bill of materials for various smartphone designs and the technical specifications of components. These enable product designers to improve their operational scheduling and strategic planning for new 
product launches. Using the E-SCM system to manage the supply chain can help product designers digitise their operations and use big data analytical tools to quickly plan and adjust production and supply chain processes, enabling them to successfully launch new products. Therefore, using information systems to support supply chain collaboration enables product designers to develop efficient business processes and avoid miscommunication and delays, thus reducing the costs and lead-times of new product introduction. Synchronising data and exchanging information using information systems greatly improve the quality, quantity and speed of the information flow, which enables CJSC to grasp the technical specifications of the new products and components and the requirements of the production processes. Thus, CJSC can help the product designers purchase high-quality components and services, improving the quality of new products. Therefore, we propose the following hypothesis.

H4. Information system integration between CJSC and product designers improves the product designers' new product launch.

\subsubsection{Impact of POF on new product launch}

The product designers' managers explained that POF plays a critical role in supporting new product launches by providing financial resources, reducing purchase costs and increasing purchasing speed. The general managers highlighted that they 'lack funds to invest in $R \& D$ and the capabilities to design and manage supply chains to launch new products'. One manager of a product designer mentioned that "we rely on CJSC to get a good price for our components because CJSC can purchase a component by aggregating multiple orders from different customers. A 500-pixel automatic-focus camera lens, for instance, has a current market price of $\$ 2.50$ each. However, with a large purchase volume, the unit price can be lowered to \$1.50. There is no way I can get this price without going through CJSC.' Thus, when a product designer receives more POF, it can greatly reduce the cash required for purchasing components, which allows the product designer to spend more resources to ensure the successful commercialisation of new product designs. Another manager highlighted that sometimes 'speed is more important than price' when purchasing components. Using POF, CJSC can purchase components and deliver them to the product designer at a very high speed. This enables new products to be launched quickly. POF also allows product designers to increase volume, expand their businesses and serve more buyers even if they have limited financial resources. Thus, they can invest more capital in their information systems, market research and customer relationship management. They can also hire more engineers and invest more resources in industrial design, thus further improving the speed of new product introduction and the quality of the new products. POF can also reduce their concerns about 
working capital, and enable them to focus on launching new products. Therefore, we propose the following hypothesis.

H5. POF received by product designers improves the product designers' new product launch.

The hypotheses and the key arguments and evidence for each hypothesis are summarised in Figure 3.

Figure 3 about here

\subsection{Quantitative study}

\subsubsection{Data collection}

We used a multilevel design. Quantitative data were collected at the project and firm levels, and from CJSC and the product designers, to test the hypotheses. Objective data about POF projects were collected from CJSC (project level), and survey data about social interaction, information system integration and new product launch were collected from the product designers (firm level). A total of 39 product designers successfully obtained POF from CJSC in the year under study. Of these, 33 were willing to participate in our research, and they conducted 207 POF projects with CJSC in the given year. Their profiles are provided in Table 1. They agreed that CJSC could share data about their POF projects with us. Thus, we collected data on 207 POF projects and 33 product designers.

Table 1 about here

A questionnaire was designed to collect data related to social interaction, information system integration and new product launch from the product designers. After consulting with CJSC and based on the findings from the qualitative study, the general managers of the product designers were chosen as the respondents. The questionnaire was sent to the 33 product designers, and all of them answered and returned the questionnaires. Objective data on the product designers (e.g., number of employees and annual sales) and the POF projects (e.g., POF, total purchasing cost, and payment terms) were collected from the E-SCM system.

\subsubsection{Variables}

Social interaction, information system integration and new product launch were measured in the questionnaire using a 7-point Likert scale. The respondents were asked about the extent to which they agreed with the statements ( $1=$ 'totally disagree'; $7=$ 'totally agree'). The measure was developed based on the findings of the qualitative study and the literature. Social interaction was measured by four items about the interactions between CJSC's and product designers' employees by which they share knowledge and collaborate on supply 
chain and business process management (Huo et al., 2013). Information system integration was measured by four items about the interconnectedness between CJSC's and product designers' information systems and the practices of sharing information and managing business processes using information systems (Huo et al., 2013). New product launch was measured by four items about quickly introducing high-quality new products to the market (Zhang and Li, 2010).

Other variables were measured using objective data. POF was measured by the proportion of the loan obtained from CJSC to the total purchasing cost of raw materials and components (Danielson and Scott, 2004). A high POF value indicates that CJSC is willing to finance a large proportion of the purchasing cost. The directors of CJSC's financing and risk control departments explained that the amount of the loan provided to a project is largely dependent on the total purchasing cost. A large-scale project with a high purchasing cost is therefore likely to receive a large loan (Danielson and Scott, 2004). Therefore, the key POF decision made by CJSC is the ratio of the loan to the total purchasing cost, which reflects its overall evaluation of the project. We also included firm size as a control variable for POF and new product launch. Large product designers tend to have higher resilience and capabilities in managing cash flows, and thus CJSC will face lower financial risks from loaning to them (Cenni et al., 2015). They may also have more resources, and hence will be more capable of launching new products (Zhang et al., 2018). We also controlled for the effects of the interest rate, uncertainty of purchase and uncertainty of receivables, as these reflect the attractiveness of a POF project (Bals, 2019). The interest rate affects the potential profit CJSC will receive from a POF project (Jia et al., 2020a). Uncertainty of purchase refers to the uncertainties of the total purchasing cost of raw materials and components and uncertainty of receivables refers to the uncertainty regarding payment from buyers. These influence the risks of a POF project and hence may affect CJSC's POF decisions. The variables and measurements are presented in Appendix III.

\subsubsection{Analysis and results}

We first conducted psychometric tests of the three multi-item constructs. We used composite reliability and Cronbach's $\alpha$ to evaluate reliability. The results show that the composite reliability values range from 0.900 to 0.921 , and the Cronbach's $\alpha$ values range from 0.877 to 0.919, indicating that the reliability of the constructs is acceptable. Average variance extracted (AVE) was used to test for convergent and discriminant validity. The AVE values range from 0.700 to 0.747 , indicating that convergent validity is acceptable. Discriminant validity is demonstrated when the square root of the AVE of each construct is higher than the 
correlations between the focal construct and each other construct. Table 2 shows the means and standard deviations of the variables, their correlations and the square roots of the AVEs. Comparisons of the correlations and square roots of the AVEs indicate that the constructs have adequate discriminant validity.

Table 2 about here

We conducted a multicollinearity test of the variables. The results reveal that the smallest tolerance is 0.692 and the largest variance inflation factor is 1.444 , indicating that multicollinearity is not a serious problem. We used multilevel structural equation modelling with robust maximum likelihood and MPLUS software to test the hypotheses because data were collected at both the firm and project levels (Mehta and Neale, 2005). The unidimensional parcels of the multi-item constructs, calculated using the principal component scores, were used in our data analysis. All of the other variables were standardised. The results of the data analysis, including the standardised path coefficients, are shown in Figure 4. The model fit indices are as follows: chi-square/df $=1.07$, comparative fit index $=0.989$, Tucker-Lewis index $=0.936$, root mean square error of approximation $=0.018$ and standardised root mean square residual $=0.026$, which are acceptable. The findings show that the $\mathrm{R}^{2}$ for POF is $29.4 \%$. Information system integration is positively associated with POF (b $=0.267, \mathrm{p}<0.05)$, whereas social interaction is negatively associated with POF $(b=-0.340$, $\mathrm{p}<0.05$ ). Therefore, $\mathrm{H} 2$ is supported, but $\mathrm{H} 1$ is not. We find that $\mathrm{R}^{2}$ for new product launch is $21.9 \%$. Social interaction $(b=0.373, p<0.05)$ and POF $(b=0.410, p<0.05)$ are positively associated with new product launch, whereas the impact of information system integration is not significant. Therefore, $\mathrm{H} 3$ and $\mathrm{H} 5$ are supported, but $\mathrm{H} 4$ is not.

Figure 4 about here

We find that the effects of firm size on POF and new product launch are not significant. As most of the product designers are SMEs, they all have limited resources to invest in supply chain management and developing resilience, even if some are larger in size. The results also show that the interest rate $(b=0.100, p<0.01)$ and uncertainty of purchase $(b=$ $0.278, \mathrm{p}<0.001)$ are positively associated with POF, whereas uncertainty of receivables $(\mathrm{b}=$ $-0.213, \mathrm{p}<0.05)$ is negatively associated with POF. A high interest rate indicates that CJSC can profit more from POF, and hence it will increase POF. Uncertainty of receivables reflects the proportion of unguaranteed payment from a buyer, and thus CJSC's losses if the buyer behaves opportunistically. A higher value of uncertainty of receivables therefore indicates 
that CJSC faces a higher risk for a POF project, and hence will provide less POF. Uncertainty of purchase reflects the volatility of the component markets and the predictability of the total purchasing cost of a POF project, and so a high level indicates that component markets change quickly and product designers may need more financial resources than expected for purchasing components. Successful component procurement ensures that product designers can deliver products to buyers according to contracts, reducing product designers' performance risk. CJSC will then provide more POF to ensure product designers can get high-quality components quickly when the uncertainty of purchase is high.

\section{Discussion and conclusions}

\subsection{Impact of information integration on POF}

The findings of the quantitative study show that social interaction and information system integration have different effects on CJSC's POF decisions. The statistical analysis reveals that social interaction is negatively associated with POF, which is inconsistent with the findings of the qualitative study. This indicates that CJSC reduces POF when a product designer relies on social interaction to integrate information. If a lender does not have realtime access to financial and operational information such as balance sheets, inventory levels and production schedules, this information asymmetry makes it difficult for the lender to determine the probability that a specific POF project will default (Stiglitz and Weiss, 1981). Although social interaction can reduce the information gap between product designers and CJSC, the efficiency of the information exchange is very low. It is extremely difficult for CJSC to acquire and process a large amount of financial and operational information in real time via social interaction (Tsai and Ghoshal, 1998). Product designers may also keep some knowledge private or provide exaggerated or even fabricated information. CJSC cannot easily verify information and monitor and control product designers and POF projects through social interaction. For example, product designers may divert POF to other projects or opportunistically declare bankruptcy. The president mentioned that one of CJSC's biggest losses from a POF project was the result of this type of fraud. Thus, compared with information system integration, social interaction is not an effective way to improve the speed, quantity and quality of the information flows in supply chains or the visibility and transparency of the operational processes in a specific POF project (Dobrzykowski and Tarafdar, 2015; Zhang et al., 2018). Thus, CJSC will view a product designer as a nontransparent borrower if it mainly relies on social interaction to integrate information, and hence it will reduce POF to control risk (Cenni et al., 2015). 
The statistical analysis reveals that information system integration significantly improves POF, which is consistent with the findings of the qualitative study. The result indicates that CJSC will increase POF for a product designer if their information systems become closely integrated. CJSC's president emphasised that digitalisation is its key strategy for managing information, physical and financial flows in supply chains. The E-SCM system is central to collecting and analysing information, supporting various operations and processes, and fuelling the rapid growth of CJSC's POF business. Through information system integration, CJSC can exchange a large volume of data with product designers in real time (Dobrzykowski and Tarafdar, 2015). The information allows CJSC to monitor and manage product designers' inventories and production and logistics processes and to plan and optimise their supply chains. Therefore, information system integration can effectively reduce information asymmetry in supply chains and allows CJSC to evaluate POF projects at the operational level and control them in real time (Jia et al., 2020a; Bals, 2019). As CJSC's president mentioned, a high degree of information system integration requires a product designer to make relationship-specific investments in IT infrastructure and operational processes, which reflects its commitment to the relationship (Huo et al., 2013). CJSC will then view this as a gesture of goodwill or guanxi, which is critical for collaboration and cooperation in Chinese culture (Li and Chen, 2019; Li et al., 2014).

\subsection{Impacts of information integration and POF on new product launch}

The results of the quantitative study indicate that social interaction is positively associated with new product launch, which is consistent with the findings of the qualitative study. CJSC can accumulate valuable tacit knowledge about market trends, technical issues and the expertise of component suppliers and assembly plants by offering integrated supply chain management services and through closely collaborating with various stakeholders in the smartphone industry (Zhang et al., 2015). Through interactions between employees, product designers can obtain and benefit from this knowledge, which is essential to the successful launch of new products (Schoenherr and Swink, 2015).

The quantitative study indicates that the impact of information system integration on new product launch is not significant, which is inconsistent with the findings of the qualitative study. Product designers cannot effectively gain knowledge about customer preferences, production processes and suppliers' capabilities through information system integration. Although information system integration greatly improves supply chain transparency and visibility, product designers and CJSC mainly exchange explicit knowledge using information systems, which enables them to jointly optimise procurement, production, and 
delivery decisions and to improve forecasting and planning (Zhang et al., 2018). Such knowledge helps product designers improve their operational processes and supply chain management (Zhang et al., 2015), and allows CJSC to manage and control POF risks. However, it cannot directly improve the launch of new products (Di Benedetto, 1999).

The quantitative study indicates that POF is positively associated with product designers' new product launch, which is consistent with the findings of the qualitative study. Product designers normally have limited resources, and they find it very difficult to obtain financial resources from banks or other financial institutions in China (Liu et al., 2015). Thus, more POF provides them with more capital to invest in human resources, $R \& D$ and supply chain management, which can help to ensure that the launch of a new product is successful (Zhang and $\mathrm{Li}, 2010)$. More POF also indicates that CJSC plays a more important role in product designers' procurement. They can therefore benefit more from CJSC's expertise and experience in supply chain management, which improves the speed of new product introduction and the quality of the new products (Schoenherr and Swink, 2015).

\subsection{Research contributions}

This study makes three main contributions to the literature. First, we provide empirical evidence on the implementation of POF in the Chinese smartphone industry from the perspectives of a POF lender and borrowers. Our findings add to the current knowledge on the interactions and collaboration between the different stakeholders of a POF project (Caniato et al., 2019; Chen et al., 2020). We also provide insights into how an innovative SCF lender (i.e., SCSP) implements and manages POF (Jia et al., 2020a; Caniato et al., 2019). The results also improve the knowledge about the applications of POF, which is an innovative SCF solution, in a specific industry (Bals, 2019; Gelsomino et al., 2016). By combining qualitative and quantitative data, we triangulate the empirical evidence to verify the findings. This allows us to fully utilise the empirical context and produce an internally valid explanation. The mixed methods design also enables us to contextualise information integration, POF and new product launch and to statistically test their relationships, thus providing a holistic view of POF implementation (Saunders et al., 2019).

Second, this study provides insights into the relationships between information integration, POF and new product launch. We reveal that POF benefits new product launch, and thus contribute to the current understanding of the performance outcomes of POF (Chen et al., 2020; Jia et al., 2020b). We find that information system integration is positively associated and social interaction negatively associated with POF. The results reveal the two routes through which SCSPs and POF borrowers integrate information and their distinct 
effects on POF, thus revealing how a SCSP makes POF decisions and jointly manages information and financial flows (Jia et al., 2020a; Bals, 2019). The findings thus highlight the importance of IT in reducing information asymmetry and supporting POF (Caniato et al., 2019).

Third, we find that social interaction is positively associated with new product launch, but information system integration has no significant effect. The results also reveal that social interaction and information system integration have different effects on POF. We therefore contribute to the literature on information integration by identifying the effects of different types of information integration on performance outcomes (Li et al., 2014; Zhang et al., 2018). We also contribute to operations-finance interface literature by examining the antecedents and consequences of POF (Wang et al., 2020).

\subsection{Managerial implications}

The findings provide guidelines on how POF lenders and borrowers can successfully adopt POF and gain more benefits from its application. We suggest a lender integrate the borrowers' information systems with its own. We recommend that a lender provides more POF to borrowers that directly use its information system or have a high level of information system integration. The lender should also offer more POF to borrowers who use information systems to synchronise data and collaborate with the lender on supply chain management. A POF lender should be aware that although social interaction with borrowers makes it easier to receive suggestions about how to improve and integrate business processes, it is not effective for managing and controlling POF projects.

We suggest cash-constrained firms that focus on launching new products use more POF. The borrowers should be aware that information system integration and social interaction, which are two mechanisms for information integration with a POF lender, have distinct effects on POF and new product launch. We recommend the borrowers closely integrate their information systems with the lender or directly use the lender's information system. However, they should be aware that although information system integration can increase POF, it will not directly contribute to the successful launch of new products. We also suggest that the borrowers encourage their employees to frequently interact with the lender to obtain support in supply chain management, solve problems and integrate business processes. However, the borrowers should be aware that although social interaction improves new product launch, relying only on social interaction to integrate information with the lender will reduce the POF they receive. Thus, we suggest borrowers integrate information through information system integration and social interaction at the same time. 


\subsection{Limitations and future research directions}

This study has four main limitations, which suggest future research directions. First, the findings are based on a case study in the smartphone industry in China. The implementation of POF may be influenced by industrial, business and institutional environments (Jia et al., 2020b), so future studies could verify and generalise the findings in other contexts. Second, this study focuses on POF. Other SCF solutions, such as dynamic discounting, inventory financing and reverse factoring, have also been extensively applied (Martin and Hofmann, 2019; Chakuu et al., 2020). Future studies could compare the findings with other SCF solutions and investigate how managers make decisions for different SCF solutions. Third, CJSC offers various supply chain management services in addition to POF. Future studies could empirically investigate the joint effects of SCF solutions and supply chain management services on the performance outcomes of SCSPs and SCF borrowers. Finally, our focus is on the interactions and collaboration between product designers and CJSC. CJSC's E-SCM system provides a platform through which supply chain members including product designers, suppliers, assemblers, service providers and buyers can collaborate to create an ecosystem. Future research could apply a longitudinal design to explore the establishment of this ecosystem and its effects on SCF solutions and the performance of supply chain members (Bals, 2019).

\section{References}

Bals, C. 2019. Toward a supply chain finance (SCF) ecosystem - Proposing a framework and agenda for future research. Journal of Purchasing and Supply Management, 25, 105117.

Cai, S., Jun, M. \& Yang, Z. 2010. Implementing supply chain information integration in China: The role of institutional forces and trust. Journal of Operations Management, $28,257-268$.

Caniato, F., Gelsomino, L. M., Perego, A. \& Ronchi, S. 2016. Does finance solve the supply chain financing problem? Supply Chain Management: An International Journal, 21, 534-549.

Caniato, F., Henke, M. \& Zsidisin, G. A. 2019. Supply chain finance: Historical foundations, current research, future developments. Journal of Purchasing and Supply Management, 25, 99-104. 
Cenni, S., Monferra, S., Salotti, V., Sangiorgi, M. \& Torluccio, G. 2015. Credit rationing and relationship lending. Does firm size matter? Journal of Banking \& Finance 53, 249265.

Chakuu, S., Masi, D. \& Godsell, J. 2020, Towards a framework on the factors conditioning the role of logistics service providers in the provision of inventory financing. International Journal of Operations \& Production Management, 40, 1225-1241.

Chen, L., Chan, H. K. \& Zhao, X. 2020. Supply chain finance: Latest research topics and research opportunities. International Journal of Production Economics, 229, 107766.

Cui, A., Zhao, M. \& Ravichandran, T. 2011. Market uncertainty and dynamic new product launch strategies: A system dynamics model. IEEE Transactions on Engineering Management 58, 530-550.

Danielson, M. G. \& Scott, J. A. 2004. Bank loan availability and trade credit demand. The Financial Review, 39, 579-600.

Di Benedetto, C. A. 1999. Identifying the key success factors in new product launch. Journal of Product Innovation Management, 16, 530-544.

Dobrzykowski, D. \& Tarafdar, M. 2015. Understanding information exchange in healthcare operations: Evidence from hospitals and patients. Journal of Operations Management, 36, 201-214.

Gelsomino, L. M., Mangiaracina, R., Perego, A. \& Tumino, A. 2016. Supply chain finance: A literature review. International Journal of Physical Distribution \& Logistics Management, 46, 393-413.

Gioia, D. A., Corley, K. G. \& Hamilton, A. L. 2012. Seeking qualitative rigor in inductive research: Notes on the Gioia methodology. Organizational Research Methods, 16, 1531.

Global Supply Chain Finance Forum 2016. Standard definitions for techniques of supply chain finance. [Online]. Available: https://iccwbo.org/publication/standarddefinitions-techniques-supply-chain-finance [Accessed 14/02/2020].

Huo, B., Han, Z., Zhao, X., Zhou, H., Wood, C. H. \& Zhai, X. 2013. The impact of institutional pressures on supplier integration and financial performance: Evidence from China. International Journal of Production Economics, 146, 82-94.

Jenkins, M. T., Craighead, C. W., Holcomb, M. C., Munyon, T. P., D.J., K. J. \& Eckerd, S. 2020. Emerging market footholds and knowledge: An examination of new product launch performance. Journal of Business Logistics, 41, 31-53. 
Jia, F., Blome, C., Sun, H., Yang, Y. \& Zhi., B. 2020a. Towards an integrated conceptual framework of supply chain finance: An information processing perspective. International Journal of Production Economics, 219, 18-30.

Jia, F., Zhang, T. \& Chen, L. 2020b. Sustainable supply chain finance: Towards a research agenda. Journal of Cleaner Production, 243, 1-14.

Kou, T., Lee, B. \& Wei, C. 2015. The role of product lean launch in customer relationships and performance in the high-tech manufacturing industry. International Journal of Operations \& Production Management, 35, 1207-1223.

Li, S. \& Chen, X. 2019. The role of supply chain finance in third-party logistics industry: A case study from China. International Journal of Logistics: Research and Applications, 22, 154-171.

Li, Y., Ye, F. \& Sheu, C. 2014. Social capital, information sharing and performance: Evidence from China. International Journal of Operations \& Production Management, 34, 1440-1462.

Liu, X., Zhou, L. \& Wu, Y. J. 2015. Supply chain finance in China: Business innovation and theory development. Sustainability, 7, 14689-14709.

Martin, J. \& Hofmann, E. 2019. Towards a framework for supply chain finance for the supply side. Journal of Purchasing and Supply Management, 25, 157-171.

Mehta, P.D. \& Neale, M.C. 2005. People are variables too: Multilevel structural equations modelling. Psychological Methods, 10, 259-284.

Reindorp, M., Tanrisever, F. \& Lange, A. 2015. Purchase order financing: Credit, commitment, and supply chain consequences SSRN: https://ssrn.com/abstract=2616812.

Saunders, M. N. K., Lewis, P. \& Thornhill, A. 2019. Research methods for business students, Harlow, U.K., Pearson Education Limited.

Schoenherr, T. \& Swink, M. 2015. The roles of supply chain intelligence and adaptability in new product launch success. Decision Science, 46, 901-936.

Song, H., Yang, X. \& Yu, K. 2020. How do supply chain network and SMEs' operational capabilities enhance working capital financing? An integrative signalling view. International Journal of Production Economics, 220, 107447.

Song, L. Z., Song, M. \& Di Benedetto, C. A. 2011. Resources, supplier investment, product launch advantages, and first product performance. Journal of Operations Management, 29, 86-104. 
Stiglitz, J. E. \& Weiss, A. 1981. Credit rationing in markets with imperfect information. American Economic Review, 71, 393-410.

Strauss, A. \& Corbin, J. 1990. Basics of qualitative research: Grounded theory procedures and techniques, Newbury Park, CA., Sage Publications.

Takeuchi, H. \& Nonaka, I. 1986. The new product development game. Harvard Business Review, Jan 1986, 137-146.

Tang, C. S., Yang, S. \& Wu, J. 2018. Sourcing from suppliers with financial constraints and performance risk. Manufacturing \& Service Operations Management, 20, 70-84.

Tsai, W. \& Ghoshal, S. 1998. Social capital and value creation: The role of intrafirm networks. Academy of Management Journal, 41, 464-476.

Villena, V. H., Revilla, E. \& Choi, T. Y. 2011. The dark side of buyer-supplier relationships: A social capital perspective. Journal of Operations Management, 29, 561-576.

Wang, J., Zhao, L. \& Huchzermeier, A. 2020. Operations-finance interface in risk management: Research evolution and opportunities. Production and Operations Management, DOI:10.1111/poms.13269.

Wu, A., Huang, B. \& Chiang, D. 2014. Support SME suppliers through buyer-backed purchase order financing. SSRN: https://ssrn.com/abstract $=2462521$.

Wuttke, D. A., Blome, C., Foerstl, K. \& Henke, M. 2013. Managing the innovation adoption of supply chain finance-Empirical evidence from six European case studies. Journal of Business Logistics, 34, 148-166.

Xu, X., Chen, X., Jia, F., Brown, S., Gong, Y. \& Xu, Y. 2018. Supply chain finance: A systematic literature review and bibliometric analysis. International Journal of Production Economics, 204, 160-173.

Yamanaka, S. 2016. Advanced lending operations and credit risk assessment using purchase order information. Bank of Japan Working Paper Series, No. 16-E-19. SSRN: https://ssrn.com/abstract $=2940011$.

Yin, R. K. 2009. Case study research, Thousand Oaks, CA, Sage.

Zhang, M., Zhao, X. \& Lyles, M. 2018. Effects of absorptive capacity, trust and information systems on product innovation. International Journal of Operations \& Production Management, 38, 493-512.

Zhang, M., Zhao, X., Lyles, M. \& Guo, H. 2015. Absorptive capacity and mass customization capability. International Journal of Operations \& Production Management, 35, 1275-1294. 
Zhang, Y. \& Li, H. 2010. Innovation search of new ventures in a technology cluster: The role of ties with service intermediaries. Strategic Management Journal, 31, 88-109.

Zhao, L. \& Huchzermeier, A. 2019. Managing supplier financial distress with advance payment discount and purchase order financing. Omega, 88, 77-90. 
Appendix I. Semi-structured interview protocol CJSC

1. Please introduce and describe the key stakeholders and processes of your supply chains.

2. What are the supply chain management services CJSC provided to supply chain members, especially product designers? Why does CJSC provide the services? Could you give us some examples? What benefits do the services bring to CJSC and the product designers?

3. How do CJSC and supply chain members, especially product designers, collaborate on supply chain management? Could you give us some examples?

4. Please introduce and describe the POF offered by CJSC. Could you give us some examples to illustrate how CJSC makes POF decisions?

5. Why does CJSC provide POF to supply chain members? What are the main drivers and enablers? What are the challenges and how they are solved?

6. How does CJSC manage and control the financial risks of POF projects? Could you give us some examples?

7. Please describe how CJSC establishes and maintains collaborative relationships with product designers when conducting POF projects. What problems has CJSC encountered and how does CJSC deal with the problems? Please give us some examples.

8. Please introduce how CJSC and product designers integrate information flows. Could you give us some examples? How does information integration affect the management of POF projects?

9. Please introduce CJSC's IT infrastructure and the functions of the information system. How does the information system support supply chain management and collaboration with supply chain members?

10. How do CJSC and product designers integrate their information systems? How does the integration influence CJSC's POF decisions and the management of POF projects?

11. How do CJSC's and product designers' employees communicate and interact with each other? What roles does this interaction play in CJSC's POF decisions and the management of POF projects?

\section{Product designers}

1. Please introduce and describe the key stakeholders and processes of your supply chains.

2. What are the key challenges of your current operations? How can CJSC help to tackle the challenges? 
3. Why do you collaborate with CJSC and apply POF? What are the key drivers for using the POF offered by CJSC? What are the differences between the POF offered by CJSC and the loans obtained from banks and other financial institutions?

4. Please describe the POF projects with CJSC. How does POF influence your operations and supply chain management processes? Please give us some examples.

5. What are the benefits and challenges when adopting POF? How do you evaluate the success of POF projects? How does POF influence product innovation?

6. What are the key practices you have adopted to facilitate the collaboration with CJSC? What are the roles played by the practices when you apply POF?

7. Have you integrated your information system with CJSC? If yes, through what means? How does the integration affect POF projects and product innovation?

8. Do your employees interact and communicate with CJSC? If yes, through what means? How does the interaction affect POF projects and product innovation?

Appendix II. Coding scheme

Table A1 about here

Appendix III. Measurement

Table A2 about here 